Original article

\title{
Evaluation of subjective sleep quality in hemodialysis patients and its association with hemodialysis timing
}

\author{
Masomeh Norozi Firoz ${ }^{1}$, Vida Shafipour ${ }^{2 *}$, Hedayat Jafari ${ }^{3}$, Seyed Hamzeh Hosseini ${ }^{4}$, Jamshid Yazdani Charati ${ }^{5}$
}

(Received: 7 May 2015; Accept: 26 Oct 2015)

\begin{abstract}
Background and Purpose: Sleep disorders are a common problem in patients undergoing hemodialysis. Poor sleep quality is considered as a potential predictor for mortality and reduced quality of life in these patients. This study aimed to evaluate subjective sleep quality in hemodialysis patients and its association with hemodialysis timing.

Methods: This descriptive-correlational study was conducted on 125 patients undergoing hemodialysis in eight teaching hospitals affiliated to Mazandaran University of Medical Sciences, Iran in 2015. Dialysis patients were selected from all the timings. Subjective sleep quality was measured using Pittsburgh Sleep Quality Index (PSQI). In addition, participants completed Beck Depression Inventory (BDI). Data analysis was performed by using Chi-square test, ANOVA and logistic regression model.

Results: In total, 210 patients were enrolled in this study, and 79 patients (63.2\%) had poor sleep quality. Moreover, no significant association was found between subjective

Sleep quality and hemodialysis timing. However, age $(\beta=0.017$, confidence interval $[\mathrm{CI}]$ : 0.003-0.034, $\mathrm{P}=0.034)$, unemployment ( $\beta=0.695$, CI: $0.0458-2.7702, \mathrm{P}=0.043)$ and residence in rural areas $(\beta=0.435, \mathrm{CI}: 0.072-1.777, \mathrm{P}=0.033)$ were identified as significant predictors for poor sleep quality.

Conclusion: According to the results of this study, poor sleep quality had no significant correlation with hemodialysis timing. Since subjective sleep quality is a common problem in hemodialysis patients, nursing care plans should be implemented to improve this parameter and quality of life in these patients.
\end{abstract}

Keywords: Hemodialysis, Sleep quality, Timing of dialysis

\section{Introduction}

Chronic kidney disease (CKD) is a clinical condition defined as irreversible loss of endogenous renal function. In order to prevent life-threatening symptoms of uremia, CKD patients undergo the permanent renal replacement therapy, (hemodialysis or kidney transplant) is used (1), to help preserving kidney function which is essential for life (2). Today, CKD and end-stage renal disease (ESRD) are considered as global public health issues. The prevalence of ESRD is on a rising trend in the Iranian population (3). Incidence of CKD has increased by $8 \%$ within the past five years (1). In one study, Nafar et al. (2008) reported the prevalence of hemodialysis to be 700,000 in Iran in 2004, while the incidence rate was estimated at 173.5 per 100000 population (3). In the United States and Iran, overall incidence of ESRD has been reported to be 330 and 250 per one million each year, respectively $(4,5)$. In Iran, population of dialysis patients reached 24,000 cases in 2014, while 5500 new cases were also diagnosed

\footnotetext{
${ }^{1}$ Student's Research Committee, Mazandaran University of Medical Sciences, Sari, Iran \& School of Nursing and Midwifery, Mazandaran University of Medical Sciences, Sari, Iran

2,* Corresponding author: Department of Medical-Surgical Nursing, Nasibeh Nursing \& Midwifery Faculty, Mazandaran University of Medical Sciences, Sari, Iran. Email: vidashafipour@yahoo.com

${ }^{3}$ Department of Medical-Surgical Nursing, Nasibeh Nursing \& Midwifery Faculty, Mazandaran University of Medical Sciences, Sari, Iran

${ }^{4}$ Psychiatry and Behavioral Sciences Research Center, Addiction Institute, Mazandaran University of Medical Sciences, Sari, Iran

${ }^{5}$ Department of Biostatistics, Faculty of Health, Mazandaran University of Medical Sciences, Sari, Iran
} 
in 2015 (6). High prevalence of CKD and ESRD leads to increased mortality and morbidity, while imposing heavy treatment costs on health care systems (7). Sleep disorders are extremely frequent among ESRD patients receiving long-term dialysis. Prevalence of sleep disorders in hemodialysis patients has been estimated at $50-80 \%$, which is relatively higher compared to non-dialysis patients $(8,9)$. Previous studies have reported potential associations between insomnia, poor sleep quality and sleep disorders with reduced quality of life and increased mortality rate in hemodialysis patients (10, 11). Insomnia, restless legs syndrome (RLS), sleep apnea and excessive daytime sleepiness (EDS) are the most common sleep disorders among these patients (12). Poor sleep quality increases the risk of cardiovascular diseases and infections (13). According to the literature, poor sleep quality is associated with physical factors, such as underlying diseases (14), uremia (15), anemia (16) and metabolic changes induced by melatonin (17). Furthermore, pharmacotherapy is assumed to interfere with quality of sleep (17). Evidence suggests that psychological factors such as depression (18-20) and anxiety (21) are directly associated with the incidence of sleep disorders. Sleep quality could also be influenced by lifestyle factors, such as sedentary lifestyle, timing of hemodialysis (17) and drinking habits (22). Dialysis timing has recently drawn the attention of researchers who believe that this parameter has a significant effect on sleep quality of hemodialysis patients. During treatment sessions, patients might start napping, which results in immobility, increased body temperature and insomnia (23). In one research, Parker et al. reported that changes in normal stages of sleep may give rise to circadian rhythm sleep and sleep-wake disorders (24). On the other hand, review of literature revealed conflicting results regarding the relationship between sleep quality and timing of dialysis. Accordingly, some studies have reported poor sleep quality in patients undergoing dialysis during the day, whereas patients with evening dialysis shifts had higher sleep quality $(25,26)$. Also, a number of studies have suggested that patients with morning dialysis shifts tend to have higher sleep quality (27). In this paper, researchers attempted to clarify the aforementioned contradictions through investigating the relationship between timing of dialysis sessions and subjective sleep quality. This study aimed to evaluate subjective sleep quality in patients undergoing hemodialysis and its association with dialysis timing.

\section{Materials and methods}

This descriptive-correlational study was conducted on 125 patients undergoing hemodialysis. Initially, 210 patients were enrolled in the study $(\alpha=0.05, d=0.05, P=0.85)$ and assessed using Beck Depression Inventory (BDI). If selected patients had BDI scores of $\geq 16$, they were excluded from the study. Finally, the sample size reached 125 patients. Participants were selected via stratified random sampling from hemodialysis departments of eight teaching hospitals affiliated to Mazandaran University of Medical Sciences, Iran during November-December 2014.

Inclusion criteria were as follows: 1) consent for participation; 2) age above 18 years; 3) patients' consciousness of the surroundings; 4) undergoing hemodialysis 2-3 times per week for 3-4 hours daily; 5 ) dialysis duration of more than three months; 6) hemodialysis at fixed sessions in the morning (8-12 a.m.), afternoon (13-17 p.m.) and evening (18-22 p.m.) shifts within the past month, and 7) dialysis patients with rotated hemodialysis sessions.

Exclusion criteria of the study were as follows: 1) traveling patients; 2) emergency cases of hemodialysis; 3) pregnancy and 4) BDI scores of $>15$. Study protocol was approved by the Ethics Committee of Mazandaran University of Medical Sciences, and objectives of the study were explained to participants. In addition, patients were fully instructed to complete the questionnaires and were assured of confidentiality terms.

Data were collected using demographic and clinical questionnaires, including BDI and Pittsburgh Sleep Quality Index (PSQI). Demographic and clinical data were age, gender, marital status, employment status, education level, place of residence, frequency and duration of dialysis, dialysis vintage, comorbidities, consumption habits and addiction, 
body mass index (BMI), dialysis adequacy $(\mathrm{Kt} / \mathrm{V})$ and blood biochemistry parameters.

PSQI consisted of 19 items to evaluate quality of nocturnal sleep in hemodialysis patients within the past month. This questionnaire is composed of seven components, as follows: subjective sleep quality, sleep latency, sleep duration, habitual sleep efficiency, sleep disturbance, daytime dysfunction and use of sleeping medications. Total scores of these indices are calculated within a score range of $0-21$, and scores of $\leq 5$ are defined as adequate sleep quality, while scores of $>5$ are defined as inadequate sleep quality. Reliability of PSQI has been confirmed using Cronbach's alpha (0.8) (28, 29), and in this study, reliability of the questionnaire was confirmed at Cronbach's alpha of 0.72 .

BDI consisted of 21 items scored on 0-3 Likert scale with total score range of 0-63. In hemodialysis patients, scores of $>15$ were indicative of depression. Patients with BDI scores of 16-63 were excluded from the study, and remaining patients $(n=125)$ were assessed in terms of subjective sleep quality.

BDI has been standardized in several studies, and correlation-coefficient of scores in two sections of the questionnaire has been reported to be $0.32-0.68$.
In addition, intra-class correlation-coefficient (ICC) has been calculated at 0.85 with validity of 0.81 using Spearman-Brown prediction formula $(30,31)$. In this study, reliability of BDI was confirmed using Cronbach's alpha (0.92).

Data analysis was performed in SPSS V.18 using descriptive and inferential statistics, Chi-square test, one-way analysis of variance (ANOVA) and logistic regression model, and $\mathrm{P}$ value of less than 0.05 was considered significant.

\section{Results}

In this study, patients were within the age range of 27-88 years with mean age of 61.56 years. 65 patients $(52 \%)$ were male, $101(80 \%)$ were married, 60 (48\%) were illiterate, 110 (88\%) were unemployed, 70 (56\%) lived in urban areas, 96 (76.8\%) had dialysis records of three times per week, $52(41.6 \%)$ had normal BMI and $70(56 \%)$ had hypertension. In addition, 35 patients $(27.9 \%)$ had dialysis sessions in the morning, 27 (21.3\%) had sessions in the afternoon, $27(21.3 \%)$ received dialysis in the evening, and $36(29.5 \%)$ had rotating dialysis schedules.

Table 1. Socio-demographic and clinical characteristics of ESRD patients in terms of hemodialysis timing

\begin{tabular}{|c|c|c|c|c|c|}
\hline Characteristics & $\begin{array}{l}\text { Morning Sessions } \\
(\mathrm{n}=\mathbf{3 5})\end{array}$ & $\begin{array}{c}\text { Evening Sessions } \\
(\mathbf{n = 2 7 )}\end{array}$ & $\begin{array}{c}\text { Night Sessions } \\
\quad(n=27)\end{array}$ & $\begin{array}{l}\text { Rotating Sessions } \\
\qquad(\mathrm{n}=\mathbf{3 6})\end{array}$ & P value \\
\hline Age (years) & 59.09 & 61.88 & 60.31 & 64.67 & 0.373 \\
\hline Gender ( Male) & $22(33.8)$ & $13(20.0)$ & $14(21.5)$ & $16(24.6)$ & 0.366 \\
\hline Marital status ( Married) & $28(27.7)$ & $19(18.8)$ & $24(23.8)$ & $30(29.7)$ & 0.625 \\
\hline Educational status ( illiterate) & $14(23.3)$ & $10(16.7)$ & $17(28.3)$ & $19(31.7)$ & 0.934 \\
\hline Employment status (Unemployed) & $29(26.4)$ & $25(22.7)$ & $22(20)$ & $34(30.9)$ & 0.945 \\
\hline Place of Residence (rural areas) & $17(30.9)$ & $15(27.3)$ & $8(14.5)$ & $15(27.3)$ & 0.607 \\
\hline Dialysis Frequency (three times per week) & $30(31.3)$ & $16(16.7)$ & $23(24)$ & $27(28.1)$ & 0.842 \\
\hline Dialysis Duration (3 until $4 \mathrm{~h}$ in day) & $34(28.1)$ & $26(21.5)$ & $26(21.5)$ & $35(28.9)$ & 0.835 \\
\hline Dialysis Vintage(months) & 62.7 & 19.84 & 17.06 & 31.5 & 0.003 \\
\hline $\mathrm{Kt} / \mathrm{V}<1.2$ & $21(23.1)$ & $20(22)$ & $25(27.5)$ & $25(27.5)$ & 0.7 \\
\hline $\mathrm{BMI}\left(\mathrm{Kg} / \mathrm{m}^{2}\right)$ & $10(19.2)$ & $10(19.2)$ & $10(19.0)$ & $10(19.0)$ & 0.620 \\
\hline PTH(pg/ml)(Above 65) & $32(28.1)$ & $23(20.2)$ & $28(24.6)$ & $31(27.7)$ & 0.948 \\
\hline Hemoglobin level (g/dl) (Low) & $33(28)$ & $23(19.5)$ & $28(23.7)$ & $34(28.8)$ & 0.822 \\
\hline BUN(mg/dl) & 79.08 & 73.57 & 83.58 & 120.861 & 0.456 \\
\hline Creatinine ( mg/dl) & 20.73 & 7.611 & 7.982 & 8.872 & 0.364 \\
\hline Phosphorus( mg/dl) & 6.8235 & 5.2269 & 5.9724 & 5.8444 & 0.364 \\
\hline Calcium ( mg/dl) & 8.8529 & 8.8115 & 8.7517 & 34.0500 & 0.073 \\
\hline $\operatorname{Albumin}(\mathrm{g} / \mathrm{dl})$ & 4.25 & 4.096 & 4.12 & 4.41 & 0.611 \\
\hline PSQI Score $(>5)$ & 20 & 18 & 17 & 24 & 0.841 \\
\hline
\end{tabular}


Table 2. Characteristics of patients with good sleep quality $(\mathrm{PSQI} \leq 5)$ and poor sleep quality $(\mathrm{PSQI}>5)$

\begin{tabular}{|c|c|c|c|c|}
\hline Characteristics & & PSQI $<5$ & PSQI $>5$ & P value \\
\hline Age (years) & & 59.09 & 61.88 & 0.380 \\
\hline \multirow{2}{*}{ Gender } & Male & 27 & 38 & \multirow{2}{*}{0.365} \\
\hline & Female & 19 & 41 & \\
\hline \multirow{4}{*}{ Marital status } & Single & 5 & 0 & \multirow{4}{*}{0.037} \\
\hline & Married & 34 & 67 & \\
\hline & Widowed & 6 & 9 & \\
\hline & divorced & 1 & 3 & \\
\hline \multirow{4}{*}{ Educational status } & Illiterate & 16 & 44 & \multirow{4}{*}{0.038} \\
\hline & Literate & 13 & 23 & \\
\hline & High school Diploma & 11 & 10 & \\
\hline & College & 6 & 2 & \\
\hline \multirow{2}{*}{ Employment status } & Employed & 11 & 4 & \multirow{2}{*}{0.005} \\
\hline & Unemployed & 35 & 75 & \\
\hline \multirow{2}{*}{ Place of Residence } & Urban Areas & 32 & 38 & \multirow{2}{*}{0.014} \\
\hline & Rural Areas & 14 & 41 & \\
\hline
\end{tabular}

On the other hand, $40.5 \%$ of patients had BDI scores of $>15$, who were excluded from DSM-IV sleep quality survey. Out of 125 patients, 79 (63.2\%) had complaints of poor sleep quality. According to the results of ANOVA, there was no significant correlation between subjective sleep quality and dialysis timing. However, a significant relationship was found between dialysis vintage and dialysis timing (morning, afternoon, evening and rotational) $(\mathrm{P}=0.003)$ (Table 1).

Regardless of dialysis timing, comparison of patients with poor sleep quality and those with good sleep quality was indicative of a significant correlation between marital status and quality of sleep $(\mathrm{P}=0.037)$. Additionally, sleep quality of patients with academic education was higher compared to illiterate patients $(\mathrm{P}=0.038)$, employed patients $(\mathrm{P}=0.005)$ and city residents $(\mathrm{P}=0.014)$ (Table 2).

In this study, predictors of PSQI scores were assessed using logistic regression analysis. Accordingly, poor sleep quality had a significant association with age $(\beta=0.017, \mathrm{CI}: 0.003-0.0070$, $\mathrm{P}=0.034)$, unemployment $(\beta=0.695$, CI 0.0458 2.7702, $\mathrm{P}=0.043$ ) and residence in urban areas ( $\beta=0.072$, CI: $0.072-1.777, P=0.033$ ). However, no significant correlation was found between other variables, such as parathyroid hormone $(\mathrm{PTH})$ and creatinine concentrations and hemodialysis timing, and quality of sleep (Table 3 ).

\section{Discussion}

The present study was performed to evaluate subjective sleep quality in patients undergoing hemodialysis and its association with dialysis timing. According to our findings, $63.2 \%$ of hemodialysis patients had poor sleep quality. Similarly, Trbojević et al. (2014) reported that $64.2 \%$ of patients undergoing hemodialysis had poor sleep quality (32). In another study, Memon at al. (2015) assessed quality of sleep in hemodialysis patients and observed that $67 \%$ of these patients had poor sleep quality (33). Findings of the current

Table 3. Independent risk factors for sleep quality according to ( logistic regression analysis)

\begin{tabular}{lcccc}
\hline & PSQI<5 & PSQI>5 & Confidence Interval 95\% & Pvalue \\
\hline Age (years) & 56.58 & 64.45 & $0.00368-0.07032$ & 0.034 \\
\hline Employment status (Unemployed) & 35 & 75 & $0.0458-2.7702$ & 0.043 \\
\hline Place of Residence (rural areas) & 14 & 42 & $0.0724-1.7776$ & 0.033 \\
\hline PTH $(\mathrm{pg} / \mathrm{ml})$ & 46 & 79 & $-4.17316-0.31916$ & 0.087 \\
\hline Creatinine( $\mathrm{mg} / \mathrm{dl})$ & 17.67 & 8.10 & $-0.19236-0.06636$ & 0.345 \\
\hline
\end{tabular}


study were indicative of no significant correlation between sleep quality and timing of hemodialysis sessions. Similarly, results obtained by Bastos et al. (2007) showed no significant relationship between sleep quality and dialysis timing, while $75 \%$ of patients were reported to have poor quality of sleep (34). In this regard, Trbojević et al. (2014) found no significant correlation between sleep quality and dialysis in morning or afternoon sessions, while $64.2 \%$ of patients were observed to have poor sleep quality (32). In another study, Cheng et al. (2011) reported no significant relationship between sleep quality and dialysis in morning, afternoon and evening sessions, while the majority of patients had poor sleep quality (35). On the other hand, findings of Memon et al. (2015) were indicative of a significant correlation between poor sleep quality and morning dialysis sessions in female and elderly patients, as well as other factors such as weight gain and dialysis duration of more than three years (33). But, in the research by Wang et al. (2013), quality of sleep was reported to be higher in patients undergoing hemodialysis in the morning. Furthermore, they concluded that depression, anxiety and consumption of tea were significantly associated with quality of sleep (27). In the study by Čengić et al. (2012), 73\% of dialysis patients had complaints of poor sleep quality, and researchers concluded that insomnia was the most common sleep disorder among these patients. However, young and employed patients with evening dialysis sessions were found to have higher sleep quality (25). In another research, Hsu et al. (2008) claimed that sleep quality significantly improved in patients receiving evening dialysis, and sleep apnea was reported as the most frequent sleep disorder in these patients (26). Sleep quality is influenced by several factors including lifestyle, physical problems and psychological disorders, such as depression and anxiety. In the current research, BDI scores were used to detect patients with depression, who were excluded from the study. In other words, our research is distinguished from similar studies in terms of considering the impact of depression on sleep quality of dialysis patients. In the present study, no significant correlation was observed between quality of sleep and consumption habits or addiction. By contrast, Wang et al. (2013) reported a significant correlation between sleep quality and consumption of tea or coffee (27). Although participants in the present study preferred morning dialysis sessions, it appears that a number of other important factors could influence sleep quality of these patients. In the aforementioned studies, patients received dialysis at certain shifts, while in the current study; we also evaluated patients with rotating dialysis shifts. Due to shortage of dialysis centers and equipment in some regions, dialysis patients who are newly diagnosed often receive treatment in the evening or rotating sessions. According to the results of the present study, there was a significant correlation between dialysis vintage and dialysis timing. In most dialysis centers, patients receive long-term treatment in morning sessions. Although patients with poor sleep quality had fewer months of dialysis on average, no significant correlation was observed between these two parameters. Similarly, Trbojević et al. (2014) reported no significant association between poor sleep quality and short dialysis vintage (32). According to the results obtained by Cheng et al. (2011), female patients undergoing hemodialysis for over seven years had lower sleep quality compared to other patients (35). In the present study, it seemed that dialysis patients could adapt with their condition and fit dialysis schedule into their daily life, and as a result, their sleep quality improved over time. Furthermore, our findings indicated that quality of sleep was lower in patients who were divorced, illiterate, unemployed and living in rural areas. In another study, Einollahi et al. (2015) stated that poor sleep quality was associated with factors such as age, female gender, unemployment, low education level, dialysis duration of more than 10 years, being a widow and diabetes (36). The majority of patients in the current study were unemployed and had low education levels, and poor quality of sleep was more prevalent among divorced patients. Moreover, we found a significant correlation between sleep quality and age, unemployment and residence in rural areas. In their research, Čengić et al. (2012) claimed that young and employed 
patients who received dialysis in the evening had higher sleep quality compared to other patients (25). In this regard, Trbojević et al. (2014) stated that poor sleep quality was significantly correlated with age, female gender and depression, while no significant association was reported between sleep quality and education status, employment status, underlying diseases and laboratory parameters (32). Due to the chronic nature of ESRD and CKD, it seems that most hemodialysis patients are elderly and unemployed. In particular, patients who must travel long distances from rural areas to dialysis centers are more likely to face stressors and suffer from poor sleep quality. In one study, Shafipour et al. (2008) reported that stress intensity tends to rise with ageing, so that stressors have a more debilitating effect on elderly dialysis patients (37). Considering the fact that no regular schedules are available for hemodialysis sessions in most dialysis centers of the province, the aforementioned factors are more likely to affect hemodialysis patients than dialysis timing.

One of the limitations of the present study was that objective sleep quality could not be assessed in hemodialysis patients due to lack of polysomnography. Therefore, it is recommended that polysomnography be used in future studies to evaluate quality of objective sleep quality in patients undergoing hemodialysis.

\section{Conclusion}

According to the results of this study, although poor sleep quality is a common problem among hemodialysis patients, no significant correlation could be found between sleep quality and timing of dialysis sessions. Nevertheless, it is recommended that health care planners pay special attention to the preference of these patients regarding the schedule of hemodialysis sessions in order to enhance their sleep quality, particularly in case of unemployed and elderly patients who travel long distances to hemodialysis centers.

\section{Conflict of interest}

None declared.

\section{Authors' contributions}

VSH designed the study, provided the important suggestions for the improvement of the first draft, revised the pape, and supervised the study process. MNF collected the data and wrote the paper. JYCH performed the statistical analysis and contributed to the study design. JH and SHH provided important suggestions for the improvement of the first draft. All the authors read and approved the manuscript.

\section{Acknowledgments}

This article was extracted from a student thesis with code number of IR.MAZUMS.REC.94.1180. Hereby, we extend our gratitude to the Research Deputy of Mazandaran University of Medical Sciences for the financial support of this study. We would also like to thank all the patients and hospital staff for assisting us in this research project.

\section{Reference}

1. Malani PN. Harrison's principles of internal medicine. JAMA 2012; 308(17):1813-4.

2. Eslami AA, Rabiei L, Khayri F, Rashidi Nooshabadi MR, Masoudi R. Sleep quality and spiritual well-being in hemodialysis patients. Iran Red Cresc Med J 2014; 16(7):e17155.

3. Nafar M, Mousavi SM, Mahdavi-Mazdeh M, Pour-RezaGholi F, Firoozan A, Einollahi B, et al. Burden of chronic kidney disease in Iran: a screening program is of essential need. Iran J Kidney Dis 2008; 2(4):183-92.

4. Hinkle JL, Cheever KH. Study guide for brunner \& suddarth's textbook of medical-surgical nursing. Philadelphia: Lippincott Williams \& Wilkins; 2013.

5. Mahdavi-Mazdeh M. The Iranian model of living renal transplantation. Kidney Int 2012; 82(6):627-34.

6. Newstext. Fars News Agency. Available from: URL: http:// WWW.farsnews.com/newstext.php?nn=13920821000454; 2015.

7. Aghighi M, Heidary Rouchi A, Zamyadi M, MahdaviMazdeh M, Rajolani H, Ahrabi S, et al. Dialysis in Iran. Iran J Kidney Dis 2008; 2(1):11-5.

8. Tel H, Tel H, Esmek M. Quality of sleep in hemodialysis patients. Dial Transplant 2007; 36(9):479-84. 
9. Pigeon WR. Diagnosis, prevalence, pathways, consequences \& treatment of insomnia. Indian J Med Res 2010; 131:321-32.

10. Elder SJ, Pisoni RL, Akizawa T, Fissell R, Andreucci VE, Fukuhara S, et al. Sleep quality predicts quality of life and mortality risk in haemodialysis patients: results from the Dialysis Outcomes and Practice Patterns Study (DOPPS). Nephrol Dial Transplant 2008; 23(3):998-1004.

11. Turkmen K, Erdur FM, Guney I, Gaipov A, Turgut F, Altintepe L, et al. Sleep quality, depression, and quality of life in elderly hemodialysis patients. Int J Nephrol Renovasc Dis 2012; 5:135-42.

12. Kosmadakis G, Medcalf JF. Sleep disorders in dialysis patients. Int J Artif Organs 2008; 31(11):919-27.

13. Mollaoğlu M. Sleep in patients with ESRD undergoing hemodialysis. Croatia: INTECH Open Access Publisher; 2011.

14. De Santo RM, Bartiromo M, Cesare MC, De Santo NG, Cirillo M. Sleeping disorders in patients with end-stage renal disease and chronic kidney disease. J Ren Nutr 2006; 16(3):224-8.

15. Chiu YL, Chuang YF, Fang KC, Liu SK, Chen HY, Yang JY, et al. Higher systemic inflammation is associated with poorer sleep quality in stable haemodialysis patients. Nephrol Dial Transplant 2009; 24(1):247-51.

16. Pai MF, Hsu SP, Yang SY, Ho TI, Lai CF, Peng YS. Sleep disturbance in chronic hemodialysis patients: the impact of depression and anemia. Ren Fail 2007; 29(6):673-7.

17. Novak M, Shapiro CM, Mendelssohn D, Mucsi I. Reviews: diagnosis and management of insomnia in dialysis patients. New Jersey: Blackwell Science Inc; 2006.

18. Afsar B, Elsurer R. The relationship between sleep quality and daytime sleepiness and various anthropometric parameters in stable patients undergoing hemodialysis. J Ren Nutr 2013; 23(4):296-301.

19. Feroze U, Martin D, Kalantar-Zadeh K, Kim JC, Reina-Patton A, Kopple JD. Anxiety and depression in maintenance dialysis patients: preliminary data of a crosssectional study and brief literature review. J Ren Nutr 2012; 22(1):207-10.

20. Guney I, Atalay H, Solak Y, Altintepe L, Toy H, Tonbul HZ, et al. Predictors of sleep quality in hemodialysis patients. Int J Artif Organs 2010; 33(3):154-60.

21. Paparrigopoulos T, Theleritis C, Tzavara C, Papadaki A. Sleep disturbance in haemodialysis patients is closely related to depression. Gen Hosp Psychiatry 2009; 31(2):175-7.

22. Chen WC, Lim PS, Wu WC, Chiu HC, Chen CH, Kuo HY, et al. Sleep behavior disorders in a large cohort of Chinese (Taiwanese) patients maintained by long-term hemodialysis. Am J Kidney Dis 2006; 48(2):277-84.

23. Parker KP, Bliwise DL, Rye DB. Hemodialysis disrupts basic sleep regulatory mechanisms: building hypotheses. Nurs Res 2000; 49(6):327-32.

24. Parker KP, Bliwise DL, Bailey JL, Rye DB. Daytime sleepiness in stable hemodialysis patients. Am J Kidney Dis 2003; 41(2):394-402.

25. Čengić B, Resić H, Spasovski G, Avdić E, Alajbegović A. Quality of sleep in patients undergoing hemodialysis. Int Urol Nephrol 2012; 44(2):557-67.

26. Hsu CY, Lee CT, Lee YJ, Huang TL, Yu CY, Lee LC, et al. Better sleep quality and less daytime symptoms in patients on evening hemodialysis: a questionnaire-based study. Artif Organs 2008; 32(9):711-6.

27. Wang MY, Chan SF, Chang LI, Chen TH, Tsai PS. Better sleep quality in chronic haemodialyzed patients is associated with morning-shift dialysis: a cross-sectional observational study. Int J Nurs Stud 2013; 50(11):1468-73.

28. Sabet R, Naghizadeh MM, Azari S. Quality of sleep in dialysis patients. Iran J Nurs Midwifery Res 2012; 17(4):270-4.

29. Buysse DJ, Reynolds CF 3rd, Monk TH, Berman SR, Kupfer DJ. The Pittsburgh Sleep Quality Index: a new instrument for psychiatric practice and research. Psychiatry Res 1989; 28(2):193-213.

30. Beck AT, Ward C, Mendelson M, Mock J, Erbaugh J. An inventory for measuring depression. Arch Gen Psychiatry 1961; 4(6):561-71.

31. Teles F, Azevedo VF, Miranda CT, Miranda MP, Teixeira Mdo C, Elias RM. Depression in hemodialysis patients: the role of dialysis shift. Clinics 2014; 69(3):198-202.

32. Trbojević-Stanković J, Stojimirović B, Bukumirić Z, Hadžibulić E, Andrić B, Đorđević V, et al. Depression and quality of sleep in maintenance hemodialysis patients. Srp Arh Celok Lek 2014; 142(7-8):437-43.

33. Menon VB, Alla P, Madhuri S, Sanathan SR, Shetty MS, Ram D. Sleep quality in end-stage renal disease patients on maintenance hemodialysis: a six month prospective survey. Int J Pharmac Sci Res 2015; 6(2):660.

34. Bastos JPC, Sousa RB, Nepomuceno LA, GutierrezAdrianzen OA, Bruin PF, Araújo ML, et al. Sleep disturbances in patients on maintenance hemodialysis: role of dialysis shift. Rev Assoc Méd Bras 2007; 53(6):492-6.

35. Chang SY, Yang TC. Sleep quality and associated factors 
in hemodialysis patients. Acta Nephrol 2011; 25(3):97-104.

36. Einollahi B, Motalebi M, Rostami Z, Nemati E, Salesi M. Sleep quality among Iranian hemodialysis patients: a multicenter study. Nephrourol Mon 2014; 7(1):e23849.
37. Shafipour V, Jafari H, Shafipour L. The relationship between stress intensity and life quality in hemodialysis patients hospitalized in Sari Iran (2008). J Sabzevar Univ Med Sci 2009; 16(3):155-60 (persian). 